\section{(1) \\ CrossMark}

\title{
Advanced pulmonary arterial hypertension: mechanical support and lung transplantation
}

\author{
Sonja Bartolome ${ }^{1}$, Marius M. Hoeper ${ }^{2}$ and Walter Klepetko ${ }^{3}$
}

Affiliations: ${ }^{1}$ Pulmonary and Critical Care Medicine, UT Southwestern Medical Center, Dallas, TX, USA. ${ }^{2}$ Dept of Respiratory Medicine, Hannover Medical School and German Centre for Lung Research, Hannover, Germany. ${ }^{3}$ Dept of Thoracic Surgery, Medical University Vienna/Vienna General Hospital, Vienna, Austria.

Correspondence: Sonja Bartolome, Pulmonary and Critical Care Medicine, UT Southwestern Medical Center, 5323 Harry Hines Boulevard Dallas, TX, 75390-8550, USA. E-mail: Sonja.BartolomeaUTSouthwestern.edu

@ERSpublications

Lung transplantation and mechanical support play key therapeutic roles in patients with advanced PAH http://ow.ly/mqfG30gMcMd

Cite this article as: Bartolome S, Hoeper MM, Klepetko W. Advanced pulmonary arterial hypertension: mechanical support and lung transplantation. Eur Respir Rev 2017; 26: 170089 [https://doi.org/10.1183/ 16000617.0089-2017].

ABSTRACT The development of targeted therapies has transformed the outlook for patients with pulmonary arterial hypertension (PAH); however, some patients fail to achieve an adequate clinical response despite receiving maximal treatment. For these patients, lung transplantation remains an important therapeutic option, and recommendations for transplantation are included in the current European Society of Cardiology/European Respiratory Society guidelines for the diagnosis and treatment of pulmonary hypertension. Although lung transplantation is not without risk, overall long-term survival rates are good and substantial improvements in quality of life have been reported for lung transplant recipients. In this review, we describe the important considerations prior to, during and after transplantation, including the role of mechanical support, in patients with advanced PAH.

\section{Introduction}

Pulmonary arterial hypertension (PAH) is a rare, progressive disease, which is characterised by remodelling of the pulmonary vasculature and increased pulmonary vascular resistance [1]. Left untreated, PAH ultimately leads to premature death from right-sided heart failure [2]. However, targeted therapies have significantly improved the outlook for PAH patients; since the introduction of the first PAH therapy (epoprostenol), 5-year survival rates for patients with idiopathic PAH (IPAH) or heritable PAH have almost doubled [3-5]. In addition to these registry data, a number of randomised controlled trials have demonstrated that some targeted therapies can improve long-term outcomes in PAH [6-8]. Despite these advances, patients in World Health Organization functional class (WHO FC) III and IV continue to have a high mortality rate [5]. Lung transplantation therefore remains an important treatment option for patients with advanced $\mathrm{PAH}[9,10]$.

Received: Aug 162017 | Accepted after revision: Nov 222017

Support statement: M.M. Hoeper is supported by the Deutsche Forschungsgemeinschaft (DFG: HO 1599/2-1). Funding was received from Actelion Pharmaceuticals Ltd, Allschwil, Switzerland. Funding information for this article has been deposited with the Crossref Funder Registry.

Conflict of interest: Disclosures can be found alongside this article at err.ersjournals.com

Provenance: Publication of this peer-reviewed article was sponsored by Actelion Pharmaceuticals Ltd, Allschwil, Switzerland (principal sponsor, European Respiratory Review issue 146).

Copyright CERS 2017. ERR articles are open access and distributed under the terms of the Creative Commons Attribution Non-Commercial Licence 4.0. 
The management of PAH is complex and requires careful risk assessment in individual patients in order to guide appropriate treatment decisions. Based on comprehensive, multi-parameter assessments, patients can be classified as low, intermediate or high risk for clinical worsening or death [9, 10]. Patients are categorised as high risk if their estimated 1-year mortality is $>10 \%$. These patients are typically in WHO FC III or IV, often with signs of severe right ventricular dysfunction, or with right ventricular failure and secondary organ dysfunction $[9,10]$. In PAH, the overall treatment goal is to achieve a low risk status: these patients will have a normal or near-normal 6-min walking distance, good quality of life and right ventricular function, and will be in WHO FC I or II $[9,10]$.

For high-risk patients, current guidelines recommend initial combination therapy, including an intravenous therapy targeting the prostacyclin pathway $[9,10]$. For patients who are in the intermediate or high-risk groups despite already receiving PAH therapy, the guidelines recommend that treatment should be escalated to dual or triple combination therapy to try to achieve a low risk status $[9,10]$.

Patients with an inadequate clinical response to initial treatment, irrespective of functional class, should be referred for lung transplantation $[9,10]$. For patients who deteriorate while on the transplant waiting list, mechanical support may serve as a bridge to therapy for a limited period of time, until a suitable donor becomes available [11]. However, early referral and comprehensive assessment are strongly advised to reduce waiting list mortality and clinical severity at the time of transplantation $[12,13]$.

In this article, the role of mechanical support and lung transplantation in the clinical management of patients with advanced $\mathrm{PAH}$ is reviewed.

\section{Pre-lung transplantation}

Timing of lung transplant referral and listing

Due to the unpredictable course of PAH, patients should be referred for lung transplantation at a relatively early stage [14]. In addition to an inadequate response to initial therapy [9, 10], other criteria for lung transplant referral include rapidly progressive disease, use of parenteral $\mathrm{PAH}$ therapy, or confirmed or suspected pulmonary veno-occlusive disease or pulmonary capillary haemangiomatosis [12]. Delayed referral and a shortage of donor organs may lead to increased mortality while patients are on the waiting list and greater disease severity at the time of transplantation $[9,10]$.

Patients who are referred for lung transplantation will be formally assessed on their suitability for surgery (general indications and contraindications for lung transplantation are provided in table 1). This is a multidisciplinary process and the entire clinical status of the patient must be considered [12, 14]. Early referral allows time for a full evaluation of the patient, as well as initiation of measures to address risk factors or potential causes of ineligibility, such as obesity or infection [12,14]. Patient evaluation should also include an assessment of exercise capability to tailor pre- and post-operative rehabilitation programmes to individual patient's needs [16]. Contraindications for lung transplantation may include failure of other organs, obesity, malignancy and a history of non-adherence to medical therapies [12, 17]. An exception to these criteria is chronic renal impairment due to venous congestion, which should not be an absolute contraindication due to evidence which shows that this condition is reversible after lung transplantation [15].

After the evaluation is complete, a decision must be made on when to list eligible patients for transplantation. Current recommendations are to list patients as soon as they display an inadequate clinical response to maximal medical therapy, including parenteral prostanoids, with severe haemodynamic impairment (cardiac index $<2 \mathrm{~L} \cdot \mathrm{min}^{-1} \cdot \mathrm{m}^{-2}$ or right atrial pressure $>15 \mathrm{mmHg}$ ), 6 -min walking distance $<350 \mathrm{~m}$, or signs of right heart failure [12]. Patients should not be placed on an active waiting list for lung transplantation until all other viable treatment options have been exhausted and the risk-benefit ratio favours this procedure over conventional medical treatment [12]. Listing should be timed to avoid extreme scenarios that are likely to increase morbidity while patients are on the waiting list, or post-operative mortality. These include progression to end-stage PAH or the necessity for bridging strategies whilst a patient awaits a donor organ $[12,17]$. Due to differences in organ allocation systems, optimal timing for listing for transplantation may vary among countries $[12,18]$.

If placed on an active waiting list, policies are in place to determine the patient's priority for a lung transplant relative to other candidates. This may be done based on waiting time, or by using a system to assign priority according to medical urgency and expected survival benefit [19]. In the USA, the policy for allocating lungs for transplantation was changed in 2005 from a system based primarily on waiting time, to one that assigns priority according to a lung allocation score (LAS) [19]. A LAS is calculated for each active registered candidate for lung transplantation aged $\geqslant 12$ years. The LAS, which ranges from 0 to 100 , is used to predict waiting list survival probability with and without a lung transplant. A higher score corresponds to greater priority for receiving a donor organ $[19,20]$. In 2015, a new LAS model was 
TABLE 1 General indications and contraindications for lung transplantation surgery in adults (all indications) [12]

Indications for surgery

High ( $>50 \%$ ) risk of death from lung disease within 2 years if lung transplantation is not performed

High ( $>80 \%$ ) likelihood of surviving at least 90 days after lung transplantation

High (>80\%) likelihood of 5 -year post-transplant survival given adequate graft function

\section{Contraindications for surgery}

Too early in the disease course

Recent history of malignancy

Poorly controlled, chronic infection with highly virulent or resistant microbes

Active Mycobacterium tuberculosis infection

Untreatable dysfunction in another organ class $\#$

Acute medical instability

Uncorrected atherosclerotic disease

Uncorrectable bleeding diathesis

Significant chest wall or spinal deformity that may cause severe restriction after transplantation

Body mass index $>35.0 \mathrm{~kg} \cdot \mathrm{m}^{-2}$

Current or a history of non-compliance to medical therapy

Psychiatric or psychological conditions associated with inability to adhere to medical therapy

Substance abuse or dependence

Absence of an adequate or reliable social support system

Severely limited functional status with poor rehabilitation potential

\#: unless combined organ transplantation can be performed, except in the case of chronic renal impairment due to venous congestion which is often reversible following lung transplantation [15].

introduced in the USA, which included modifications to the variables used to calculate the LAS, as well as the relative weight of the variables used to predict the risk of death $[21,22]$. It is anticipated that this will improve the survival prediction for all patients, but will have the greatest impact on patients with a diagnosis of pulmonary vascular disease [21].

Allocation policies based on the LAS have also been adopted in Germany, and more recently, the Netherlands [22]. In the USA and Germany, the introduction of the LAS has shortened the time to transplantation and decreased the risk of waiting list mortality for many diseases [23, 24], including IPAH $[25,26]$. Despite this observation, the LAS may not fully reflect disease severity in patients with IPAH $[14,27]$. This has led to revisions to the LAS, allowing PAH patients who demonstrate signs of right heart failure or extreme disease severity to be granted an exception to the standard LAS criteria (figure 1) $[24,29]$. The exception to the LAS was introduced for patients in whom the calculated LAS may not adequately reflect the urgency and expected outcome following lung transplantation [24]. The introduction of a high priority allocation programme in France has also significantly reduced waiting-list mortality for pulmonary hypertension (PH) patients [30]. In the USA, patients may be granted an exception by their local regional review board even if they are not actively hospitalised or deteriorating. However, there is regional variability in the ability to grant these exceptions.

A criticism of the LAS is that it may increase the number of transplant recipients with poorer survival probabilities by prioritising those with greater urgency. If this is the case, any clinical benefit of shortening the time to transplantation may be diminished by poorer overall survival post-transplantation [20, 31]. Moreover, demographic characteristics and risk factors for pre-and post-transplant mortality in patients on waiting lists are likely to change over time. These considerations emphasise the need for ongoing refinement and re-evaluation of lung allocation policies $[12,19]$.

Geographic location may also affect a patient's waiting list time. Recent data have shown that a tendency to distribute organs locally has led to significant numbers of patients with a low LAS score receiving locally obtained organs [32]. This suggests that improvements in organ sharing across geographic regions are required to facilitate the most appropriate allocation.

\section{Management of patients ineligible for transplantation}

For patients with advanced $\mathrm{PAH}$ who are ineligible for transplantation, the remaining surgical options are limited. In exceptional cases, balloon atrial septostomy (BAS) may be considered in experienced centres $[33,34]$. If BAS is contraindicated, a transcatheter Potts shunt may be performed in rare cases; however, this procedure is experimental and carries very high levels of risk [33]. These procedures are described in more detail below. In patients with end-stage $\mathrm{PAH}$ for whom all available treatment options have been exhausted, palliative care should be considered [35]. 


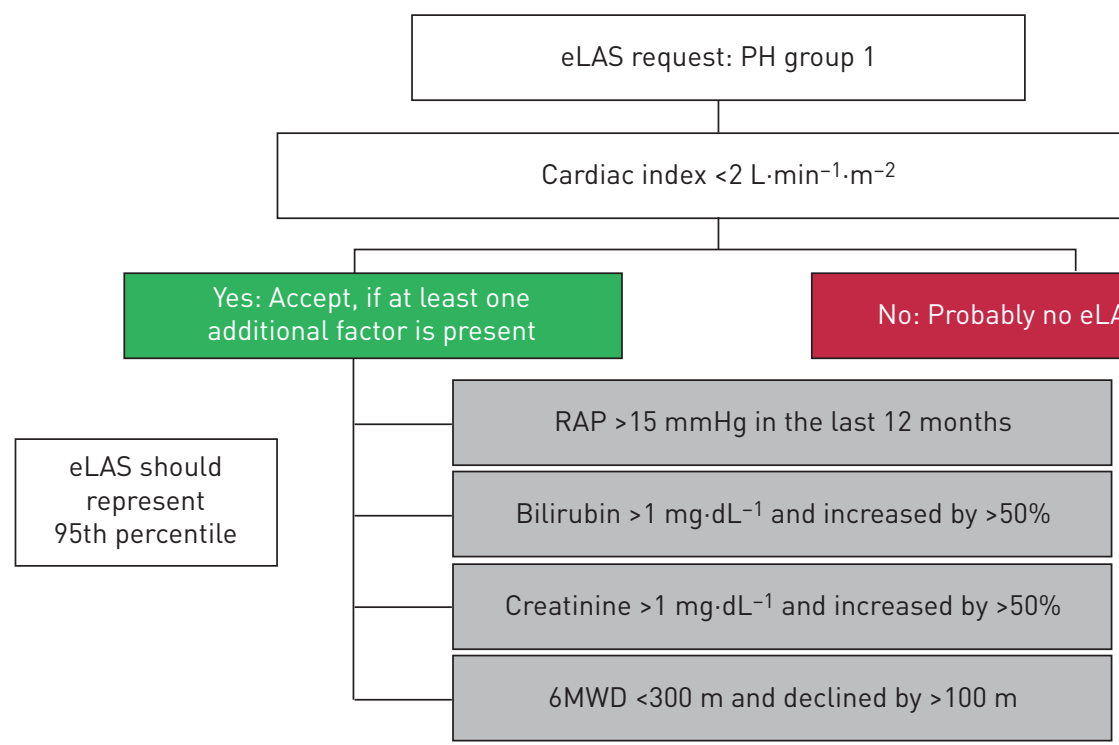

FIGURE 1 Circumstances under which pulmonary arterial hypertension patients with markers of severe disease can be granted an exceptional lung allocation score (eLAS) [28]. 6MWD: 6-min walking distance; $\mathrm{PH}$ : pulmonary hypertension; RAP: right atrial pressure.

\section{Bridging to transplantation}

There is generally a shortage of donor organs and, in $\mathrm{PAH}$, mortality whilst on the transplant waiting list remains relatively high compared with other conditions $[9,10]$. For many eligible patients, bridging to transplant may be necessary to keep the patient alive whilst on the waiting list and to avoid irreversible end organ damage [36]. Bridging can be performed using a number of techniques, which are discussed in detail below.

\section{Balloon atrial septostomy}

For PAH patients in WHO FC III or IV, the current guidelines suggest that BAS should be considered after failure of maximal medical therapy $[9,10]$. This is a percutaneous procedure by which a right-to-left shunt is created by balloon dilatation of the atrial septum [9, 10, 37]. It results in decompression of the right heart chambers and can increase left ventricular preload and cardiac output [9, 10]. Published studies have demonstrated that BAS can be used successfully to bridge patients to lung transplant [37, 38]. However, there is a risk of peri-operative mortality associated with BAS [37] and the guidelines recommend that the procedure should only be performed in an experienced centre $[9,10]$.

\section{Potts shunt}

The right heart can also be decompressed by performing a transcatheter Potts shunt, whereby a direct anastomosis is created between the left pulmonary artery and the descending aorta [33]. In addition to more reliable shunting, a theoretical advantage is that direct shunting (into the descending aorta) avoids exposing the brain and myocardium to desaturated blood, which can occur following atrial septostomy $[33,39]$. Potts shunt has shown promise as a rescue therapy in paediatric patients with suprasystemic pulmonary arterial pressures [40]. However, the procedural mortality rate is likely to be high in adults and the procedure should be reserved for patients with a contraindication for BAS. Although some benefits have been shown in a small case series in adult patients, the efficacy and long-term safety of this procedure requires cautious study [39].

\section{Extracorporeal membrane oxygenation}

Extracorporeal membrane oxygenation (ECMO) is an invasive technique used to support cardiopulmonary function [11] and which may be used as a bridging therapy in patients with $\mathrm{PH}$ with persistent right ventricular failure in the absence of a response to medical treatment [36]. Originally, the use of ECMO was limited by complications that accompany prolonged sedation and mechanical ventilation, such as pneumonia and septicaemia [41]. To avoid these problems, ECMO has more recently been applied under local anaesthesia in awake and spontaneously breathing patients [36, 41, 42]. This awake ECMO avoids the increased risks to the right heart associated with long-term mechanical ventilation and intubation, and permits the patient to begin pre-operative physiotherapy, which may improve post-transplantation outcomes $[36,41,42]$. 
In order to bridge patients with PAH to transplant, ECMO is most commonly used in a peripheral veno-arterial setting. An alternative is the central use of oxygenator membranes that are implanted between the pulmonary artery and left atrium, creating a parallel circuit where blood can be oxygenated while unloading the right ventricle $[36,43,44]$. This device can immediately stabilise patients with right ventricular failure and permits active rehabilitation [36]. Although suitable for patients who are predicted to have a long waiting time on the transplant list [36], it requires a sternotomy or thoracotomy under general anaesthesia for implantation $[36,43]$. This may be problematic in PAH because of the substantial haemodynamic risk of general anaesthesia in patients with right heart failure [41] and often requires the use of veno-arterial ECMO prior to surgery.

\section{Peri-lung transplantation}

Bilateral lung transplantation is the standard procedure in PAH patients $[9,10]$ as it is associated with comparable or better results than heart-lung transplantation and waiting times for lungs alone are generally shorter than waiting times for both heart and lungs [45-47]. As a result, heart-lung transplantation is usually only performed for PAH patients with uncorrectable congenital heart disease [45]. Single-lung transplantation for PH is now rarely performed due to adverse post-operative outcomes, including pulmonary oedema, graft dysfunction, ventilation/perfusion mismatching and the need for prolonged ventilation and mechanical support $[47,48]$.

Almost all patients will require haemodynamic and respiratory support during the operative period. Until recently, cardiopulmonary bypass (CPB) had been the standard method [49]. However, it is associated with an increased peri- and post-procedural risk of bleeding due to heparinisation, as well as an increased risk of primary graft dysfunction resulting from the systemic inflammatory response [49]. To reduce these risks, ECMO has been adopted as an alternative to CPB in the intra-operative setting. As well as lowering the risk of a systemic inflammatory response, this technique may also reduce the risk of bleeding, as full heparinisation is not required [49]. A retrospective comparison of outcomes for patients treated with CPB or ECMO during lung transplantation demonstrated that ECMO was associated with improved survival and reduced post-procedural complication rates compared with CPB. ECMO can also be extended to provide support during the post-operative period, to minimise haemodynamic instability during this critical phase $[49,50]$. For these reasons, ECMO has replaced CPB in lung transplantation and is now the standard cardiopulmonary support procedure used in most transplantation centres [49, 51-53].

\section{Post-lung transplantation}

Post-operative management

The immediate post-operative management of PAH patients can be challenging. There are a number of factors that may contribute to this; however, the pathophysiological changes that occur post-transplant are perhaps the most important [27]. In $\mathrm{PAH}$ patients, lung transplantation leads to normalisation of pulmonary vascular resistance, an immediate increase in cardiac output, and an increase in left ventricular filling. This can lead to left ventricular failure, as the left ventricle may not be able to accommodate a normal or high cardiac output in the immediate post-operative period [54,55]. The scale of this complication was demonstrated in a retrospective single-centre study, where almost a third of PAH patients who underwent lung transplantation from 2008 to 2012 experienced left ventricular dysfunction (five out of 16 patients) [56]. To avoid left ventricular dysfunction, use of ECMO can be prolonged into the post-operative period in order to allow time for the left ventricle to adapt to the altered haemodynamics that occur after transplantation [54].

Primary graft dysfunction is another important complication that can occur in the early post-operative period and is a significant cause of early morbidity and mortality following lung transplantation [57]. It has previously been reported that $\mathrm{PH}$ in the recipient is a significant risk factor for primary graft dysfunction $[58,59]$. Subsequently, in a recent study by PORTEOus et al. [60], a number of donor, recipient and operative characteristics were shown to be associated with the development of primary graft dysfunction in patients with PH. These included higher recipient body mass index, female sex, pre-operative pulmonary artery pressure, right atrial pressure and creatinine level at transplant, donor tobacco exposure, use of cardiopulmonary bypass, transfusion volume and reperfusion fraction of inspired oxygen. Patients should be monitored closely for the development of primary graft dysfunction [14] and may benefit from treatments aimed at reducing post-surgical reperfusion injury. These include fluid management, altered strategies of ventilation to reduce airway pressure including positive end-expiratory pressure, use of inhaled vasodilators, beta-blockers to limit perfusion, and ECMO to provide the lungs with a period of low-perfusion recovery [57, 61].

$\mathrm{PAH}$ patients who have undergone lung transplantation can also be affected by passive hepatic congestion leading to the development of ascites and coagulopathies. Ascites may need to be drained to assist with 
ventilator weaning. Furthermore, patients may require treatment with vitamin $\mathrm{K}$ and coagulation factors to prevent bleeding complications.

\section{Post-operative outcomes}

Following lung transplantation, patients with advanced PAH experience a reversal in right ventricular failure and amelioration in symptoms [62]. The response of the right ventricle is immediate and patients who are admitted for surgery whilst receiving combination therapy are able to discontinue PAH therapies and demonstrate striking reductions in pulmonary artery pressures [14,63]. However, as described earlier, the immediate post-operative period can be difficult for PAH patients due to the rapid physiological changes that occur upon implantation of donor lungs. This is reflected in the most recently published data from the International Society for Heart and Lung Transplant (ISHLT), which reported that for patients receiving a lung transplant between 1990 and 2014, the mortality risk in the first 3 months is higher for IPAH $(23 \%)$ than for many other indications, including chronic obstructive pulmonary disease (9\%) or cystic fibrosis (9\%) [64]. However, recent advances in peri- and post-operative management have resulted in considerable improvements in early post-transplant survival rates. Across all indications, 3-month survival post-lung transplant has increased from 82\% (transplants performed between 1990 and 1998) to 91\% (transplants performed between 2009 and 2013) [64]. In the PH setting, considerable improvements in early mortality have been reported by some specialist centres. For example, in a cohort of PH patients receiving a bilateral lung transplant combined with post-operative ECMO in a specialist centre after 2010, post-transplant survival rates at 3 and 12 months were reported to be $100 \%$ and $96 \%$, respectively [54]. Similar results were obtained from a recent study of IPAH patients receiving prolonged ECMO after bilateral lung transplantation. In this study, survival rates at 3 months, 1 year, 3 years and 5 years were $93 \%, 90 \%, 87 \%$ and $87 \%$, respectively [65].

For PAH patients who survive the early post-transplant period, long-term outcomes are good and are frequently better than for many other indications. Data from the ISHLT registry have demonstrated that for primary transplant patients with IPAH who survived to 1 year, conditional median survival was 10.0 years. In contrast, conditional median survival for patients with chronic obstructive pulmonary disease or interstitial lung disease was only 7.0 and 6.9 years, respectively [64]. Although the early post-operative period is clearly the time of greatest risk, lung transplant recipients are frequently affected by a number of serious long-term complications, including bronchiolitis obliterans syndrome (BOS), malignancies and infection [66]. According to the ISHLT registry, almost half (41.5\%) of all lung transplant survivors develop BOS within 5 years of transplant [66] and it remains a leading cause of death in the long-term, accounting for $21.5 \%$ of all deaths that occur more than 10 years post-transplant [66]. A similar proportion of deaths in IPAH patients that occur more than 10 years post-transplant are attributable to BOS (21.7\%) [66]. Other long-term complications affecting transplant patients include systemic hypertension, hyperlipidaemia, renal dysfunction and diabetes, all of which occur commonly as a consequence of immunosuppression therapies [67].

Despite the short and long-term risks associated with lung transplantation, survival rates post-transplantation are improving over time for all indications. This is clearly illustrated in data from the ISHLT registry, which recently demonstrated that median survival times for all patients who have undergone lung transplantation have increased from 4.3 years in 1990 to 1997, to 6.3 years in 2005 to 2012 [68]. In addition to increased survival, significant and substantial improvements in health-related quality of life, predominantly in domains related to physical health and functioning, have been reported post-lung transplant in patients with end-stage lung disease [69]. Patients who returned to work after lung transplantation showed further improvements in short-term quality of life compared with those patients who did not [70]. Patients should, therefore, be encouraged to return to work post-transplantation, as long as their job is not a risk to their health [70].

\section{Conclusions}

For PAH patients who show an inadequate treatment response to medical therapy, lung transplantation is an important option and outcomes for patients post-transplantation continue to improve due to advances in surgical techniques and peri- and post-operative management. However, timely referral for transplantation is critical, and eligible patients should be listed immediately following an inadequate response to maximal combination medical therapy. Despite the benefits, lung transplantation is not without risk; a careful risk/benefit decision must be taken to determine the most appropriate treatment strategy in each patient with advanced PAH.

\section{Acknowledgements}

The authors would like to thank James Glasper (nspm Ltd, Meggen, Switzerland) for medical writing assistance, funded by Actelion Pharmaceuticals Ltd (Allschwil, Switzerland). 


\section{References}

1 Farber HW, Loscalzo J. Pulmonary arterial hypertension. N Engl J Med 2004; 351: 1655-1665.

2 McLaughlin VV, McGoon MD. Pulmonary arterial hypertension. Circulation 2006; 114: 1417-1431.

3 D'Alonzo GE, Barst RJ, Ayres SM, et al. Survival in patients with primary pulmonary hypertension. Results from a national prospective registry. Ann Intern Med 1991; 115: 343-349.

4 Sitbon $\mathrm{O}$, Humbert $\mathrm{M}$, Nunes $\mathrm{H}$, et al. Long-term intravenous epoprostenol infusion in primary pulmonary hypertension: prognostic factors and survival. J Am Coll Cardiol 2002; 40: 780-788.

5 Farber HW, Miller DP, Poms AD, et al. Five-year outcomes of patients enrolled in the REVEAL Registry. Chest 2015; 148: 1043-1054.

6 Pulido T, Adzerikho I, Channick R, et al. Macitentan and morbidity and mortality in pulmonary arterial hypertension. N Engl J Med 2013; 369: 809-818.

7 Sitbon O, Channick R, Chin KM, et al. Selexipag for the treatment of pulmonary arterial hypertension. $N$ Engl $J$ Med 2015; 373: 2522-2533.

8 Galiè N, Barbera JA, Frost AE, et al. Initial use of ambrisentan plus tadalafil in pulmonary arterial hypertension. $N$ Engl J Med 2015; 373: 834-844.

9 Galiè N, Humbert M, Vachiery JL, et al. 2015 ESC/ERS Guidelines for the diagnosis and treatment of pulmonary hypertension: The Joint Task Force for the Diagnosis and Treatment of Pulmonary Hypertension of the European Society of Cardiology (ESC) and the European Respiratory Society (ERS). Eur Respir J 2015; 46: 903-975.

10 Galiè N, Humbert M, Vachiery JL, et al. 2015 ESC/ERS Guidelines for the diagnosis and treatment of pulmonary hypertension: The Joint Task Force for the Diagnosis and Treatment of Pulmonary Hypertension of the European Society of Cardiology (ESC) and the European Respiratory Society (ERS). Eur Heart J 2016; 37: 67-119.

11 Del Sorbo L, Boffini M, Rinaldi M, et al. Bridging to lung transplantation by extracorporeal support. Minerva Anestesiol 2012; 78: 243-250.

12 Weill D, Benden C, Corris PA, et al. A consensus document for the selection of lung transplant candidates: 2014-an update from the Pulmonary Transplantation Council of the International Society for Heart and Lung Transplantation. J Heart Lung Transplant 2015; 34: 1-15.

13 Galiè N, PA C, Frost A. Updated treatment algorithm of pulmonary arterial hypertension. J Am Coll Cardiol 2013; 62: D60-D72.

14 George MP, Champion HC, Pilewski JM. Lung transplantation for pulmonary hypertension. Pulm Circ 2011; 1: $182-191$.

15 Navis G, Broekroelofs J, Mannes GP, et al. Renal hemodynamics after lung transplantation. A prospective study. Transplantation 1996; 61: 1600-1605.

16 Wickerson L, Rozenberg D, Janaudis-Ferreira T, et al. Physical rehabilitation for lung transplant candidates and recipients: An evidence-informed clinical approach. World J Transplant 2016; 6: 517-531.

17 Keogh AM, Mayer E, Benza RL, et al. Interventional and surgical modalities of treatment in pulmonary hypertension. J Am Coll Cardiol 2009; 54: S67-S77.

18 Orens JB, Estenne M, Arcasoy S, et al. International guidelines for the selection of lung transplant candidates: 2006 update-a consensus report from the Pulmonary Scientific Council of the International Society for Heart and Lung Transplantation. J Heart Lung Transplant 2006; 25: 745-755.

19 Egan TM, Murray S, Bustami RT, et al. Development of the new lung allocation system in the United States. Am J Transplant 2006; 6: 1212-1227.

20 Afshar K. Time to lung transplantation: Lung Allocation Score and other factors. J Pulm Respir Med 2012; 2: e110.

21 Valapour M, Skeans MA, Heubner BM, et al. OPTN/SRTR 2013 Annual Data Report: lung. Am J Transplant 2015; 15 Suppl 2: 1-28.

22 Gottlieb J. Lung allocation. J Thorac Dis 2017; 9: 2670-2674.

23 Chen H, Shiboski SC, Golden JA, et al. Impact of the lung allocation score on lung transplantation for pulmonary arterial hypertension. Am J Respir Crit Care Med 2009; 180: 468-474.

24 Gottlieb J, Smits J, Schramm R, et al. Lung transplantation in Germany since the introduction of the Lung Allocation Score. Dtsch Arztebl Int 2017; 114: 179-185.

25 Schaffer JM, Singh SK, Joyce DL, et al. Transplantation for idiopathic pulmonary arterial hypertension: improvement in the lung allocation score era. Circulation 2013; 127: 2503-2513.

26 Egan TM, Edwards LB. Effect of the lung allocation score on lung transplantation in the United States. J Heart Lung Transplant 2016; 35: 433-439.

27 George P, Davis RD, Klepetko W. Lung Transplantation in Pulmonary Hypertension. In: Benza MD, ed. Pulmonary Hypertension and Right Heart Failure. New York, Elsevier, 2015; pp. 308-321.

28 Olsson KM, Halank M, Egenlauf B, et al. Dekompensierte Rechtsherzinsuffizienz, Intensiv- und PerioperativManagement bei Patienten mit pulmonaler Hypertonie [Decompensated right heart failure, intensive care and perioperative management in patients with pulmonary hypertension]. Dtsch Med Wochenschr 2016; 141: S42-S47.

29 Chan KM. Idiopathic pulmonary arterial hypertension and equity of donor lung allocation in the era of the lung allocation score: are we there yet? Am J Respir Crit Care Med 2009; 180: 385-387.

30 Savale L, Le Pavec J, Mercier O, et al. Six-years experience with high priority allocation program for lung and heart-lung transplantation in pulmonary hypertension. J Heart Lung Transplant 2015; 34: S160.

31 Liu V, Zamora MR, Dhillon GS, et al. Increasing lung allocation scores predict worsened survival among lung transplant recipients. Am J Transplant 2010; 10: 915-920.

32 Iribarne A, Meltzer DO, Chauhan D, et al. Distribution of donor lungs in the United States: a case for broader geographic sharing. Clin Transplant 2016; 30: 688-693.

33 Bhamra-Ariza P, Keogh AM, Muller DW. Percutaneous interventional therapies for the treatment of patients with severe pulmonary hypertension. J Am Coll Cardiol 2014; 63: 611-618.

34 Sandoval J, Gaspar J, Pena H, et al. Effect of atrial septostomy on the survival of patients with severe pulmonary arterial hypertension. Eur Respir J 2011; 38: 1343-1348.

35 Hoeper MM, Granton J. Intensive care unit management of patients with severe pulmonary hypertension and right heart failure. Am J Respir Crit Care Med 2011; 184: 1114-1124.

36 Granton J, Mercier O, De Perrot M. Management of severe pulmonary arterial hypertension. Semin Respir Crit Care Med 2013; 34: 700-713. 

on survival and associated outcomes. J Heart Lung Transplant 2015; 34: 376-380. Kurzyna M, Dabrowski M, Bielecki D, et al. Atrial septostomy in treatment of end-stage right heart failure in patients with pulmonary hypertension. Chest 2007; 131: 977-983.

39 Esch JJ, Shah PB, Cockrill BA, et al. Transcatheter Potts shunt creation in patients with severe pulmonary arterial hypertension: initial clinical experience. J Heart Lung Transplant 2013; 32: 381-387.

40 Baruteau AE, Serraf A, Levy M, et al. Potts shunt in children with idiopathic pulmonary arterial hypertension: long-term results. Ann Thorac Surg 2012; 94: 817-824.

41 Olsson KM, Simon A, Strueber M, et al. Extracorporeal membrane oxygenation in nonintubated patients as bridge to lung transplantation. Am J Transplant 2010; 10: 2173-2178.

42 Abrams DC, Brodie D, Rosenzweig EB, et al. Upper-body extracorporeal membrane oxygenation as a strategy in decompensated pulmonary arterial hypertension. Pulm Circ 2013; 3: 432-435.

43 Strueber M, Hoeper MM, Fischer S, et al. Bridge to thoracic organ transplantation in patients with pulmonary arterial hypertension using a pumpless lung assist device. Am J Transplant 2009; 9: 853-857.

44 Schmid C, Philipp A, Hilker M, et al. Bridge to lung transplantation through a pulmonary artery to left atrial oxygenator circuit. Ann Thorac Surg 2008; 85: 1202-1205.

45 de Perrot M, Granton JT, McRae K, et al. Outcome of patients with pulmonary arterial hypertension referred for lung transplantation: a 14-year single-center experience. J Thorac Cardiovasc Surg 2012; 143: 910-918.

46 Fadel E, Mercier O, Mussot S, et al. Long-term outcome of double-lung and heart-lung transplantation for pulmonary hypertension: a comparative retrospective study of 219 patients. Eur J Cardiothorac Surg 2010; 38: 277-284.

47 Lala A. Transplantation in end-stage pulmonary hypertension (Third International Right Heart Failure Summit part 3). Pulm Circ 2014; 4: 717-727.

48 Bando K, Keenan RJ, Paradis IL, et al. Impact of pulmonary hypertension on outcome after single-lung transplantation. Ann Thorac Surg 1994; 58: 1336-1342.

49 Ius F, Kuehn C, Tudorache I, et al. Lung transplantation on cardiopulmonary support: venoarterial extracorporeal membrane oxygenation outperformed cardiopulmonary bypass. J Thorac Cardiovasc Surg 2012; 144: 1510-1516.

50 Pereszlenyi A, Lang G, Steltzer H, et al. Bilateral lung transplantation with intra- and postoperatively prolonged ECMO support in patients with pulmonary hypertension. Eur J Cardiothorac Surg 2002; 21: 858-863.

51 Machuca TN, Cypel M, Keshavjee S. Cardiopulmonary bypass and extracorporeal life support for emergent intraoperative thoracic situations. Thorac Surg Clin 2015; 25: 325-334.

52 Biscotti M, Yang J, Sonett J, et al. Comparison of extracorporeal membrane oxygenation versus cardiopulmonary bypass for lung transplantation. J Thorac Cardiovasc Surg 2014; 148: 2410-2415.

53 Bermudez CA, Shiose A, Esper SA, et al. Outcomes of intraoperative venoarterial extracorporeal membrane oxygenation versus cardiopulmonary bypass during lung transplantation. Ann Thorac Surg 2014; 98: 1936-1942.

54 Tudorache I, Sommer W, Kuhn C, et al. Lung transplantation for severe pulmonary hypertension--awake extracorporeal membrane oxygenation for postoperative left ventricular remodelling. Transplantation 2015; 99: 451-458.

55 Birsan T, Kranz A, Mares P, et al. Transient left ventricular failure following bilateral lung transplantation for pulmonary hypertension. J Heart Lung Transplant 1999; 18: 304-309.

56 Gupta S, Torres F, Bollineni S, et al. Left ventricular dysfunction after lung transplantation for pulmonary arterial hypertension. Transplant Proc 2015; 47: 2732-2736.

57 Whitson BA, Nath DS, Johnson AC, et al. Risk factors for primary graft dysfunction after lung transplantation. $J$ Thorac Cardiovasc Surg 2006; 131: 73-80.

58 Kuntz CL, Hadjiliadis D, Ahya VN, et al. Risk factors for early primary graft dysfunction after lung transplantation: a registry study. Clin Transplant 2009; 23: 819-830.

59 Diamond JM, Lee JC, Kawut SM, et al. Clinical risk factors for primary graft dysfunction after lung transplantation. Am J Respir Crit Care Med 2013; 187: 527-534.

60 Porteous MK, Lee JC, Lederer DJ, et al. Clinical risk factors and prognostic model for primary graft dysfunction after lung transplantation in patients with pulmonary hypertension. Ann Am Thorac Soc 2017; 14: $1514-1522$.

61 Altun GT, Arslantas MK, Cinel I. Primary graft dysfunction after lung transplantation. Turk J Anaesthesiol Reanim 2015; 43: 418-423

62 Gorter TM, Verschuuren EAM, van Veldhuisen DJ, et al. Right ventricular recovery after bilateral lung transplantation for pulmonary arterial hypertension. Interact Cardiovasc Thorac Surg 2017; 24: 890-897.

63 Katz WE, Gasior TA, Quinlan JJ, et al. Immediate effects of lung transplantation on right ventricular morphology and function in patients with variable degrees of pulmonary hypertension. J Am Coll Cardiol 1996; 27: 384-391.

64 Yusen RD, Edwards LB, Kucheryavaya AY, et al. The Registry of the International Society for Heart and Lung Transplantation: Thirty-second Official Adult Lung and Heart-Lung Transplantation Report - 2015; focus theme: early graft failure. J Heart Lung Transplant 2015; 34: 1264-1277.

65 Moser B, Jaksch P, Taghavi S, et al. Lung transplantation for idiopathic pulmonary arterial hypertension on intraoperative and postoperatively prolonged extracorporeal membrane oxygenation provides optimally controlled reperfusion and excellent outcome. Eur J Cardiothorac Surg 2017; in press [https://doi.org/10.1093/ejcts/ezx212].

66 Yusen RD, Edwards LB, Dipchand AI, et al. The Registry of the International Society for Heart and Lung Transplantation: Thirty-third Adult Lung and Heart-Lung Transplant Report - 2016; focus theme: primary diagnostic indications for transplant. J Heart Lung Transplant 2016; 35: 1170-1184.

67 Yusen RD, Christie JD, Edwards LB, et al. The Registry of the International Society for Heart and Lung Transplantation: Thirtieth Adult Lung and Heart-Lung Transplant Report - 2013; focus theme: age. J Heart Lung Transplant 2013; 32: 965-978.

68 Yusen RD, Edwards LB, Kucheryavaya AY, et al. The Registry of the International Society for Heart and Lung Transplantation: Thirty-first Adult Lung and Heart-Lung Transplant Report - 2014; focus theme: retransplantation. J Heart Lung Transplant 2014; 33: 1009-1024.

69 Singer JP, Chen J, Blanc PD, et al. A thematic analysis of quality of life in lung transplant: the existing evidence and implications for future directions. Am J Transplant 2013; 13: 839-850.

70 Suhling $\mathrm{H}$, Knuth $\mathrm{C}$, Haverich A, et al. Employment after lung transplantation - a single-center cross-sectional study. Dtsch Arztebl Int 2015; 112: 213-219. 